\title{
Significance of serum early pregnancy factor concentrations during pregnancy and embryonic development in Sminthopsis macroura (Spencer) (Marsupialia: Dasyuridae)
}

\author{
Y. P. Cruz ${ }^{1}$, L. Selwood ${ }^{2}$, H. Morton ${ }^{3}$ and A. C. Cavanagh ${ }^{3}$ \\ ${ }^{1}$ Department of Biology, Oberlin College, Oberlin, OH 44074-1082, USA; ${ }^{2}$ Department of \\ Zoology, La Trobe University, Bundoora 3083, VIC, Australia; and ${ }^{3}$ Department of Surgery, \\ University of Queensland, Royal Brisbane Hospital, Brisbane 4029, QLD, Australia
}

\begin{abstract}
Marsupial pregnancy differs from that in eutherians in duration, placentation and hormonal profile so much so that maternal recognition of pregnancy may not occur in polyovular marsupials. However, a comparison of gravid and non-gravid uteri reveals differences indicative of histological and physiological adaptations to pregnancy. In the present study, the hypothesis that embryo-maternal signalling occurs in polyovular marsupials was tested by examining serum from non-pregnant and pregnant Sminthopsis macroura for the presence of early pregnancy factor (EPF), a serum protein secreted by the ovary in response to the presence of a newly fertilized egg in the oviduct. EPF is detectable in the serum of pregnant, but not in non-pregnant, females in all eutherians studied to date. In the present study, EPF was detected in $S$. macroura
\end{abstract}

serum by the rosette inhibition test during the first 9 days of the 10.7 day gestation period in this marsupial. However, EPF was not detected on day 10, just before parturition, or in non-pregnant or preovulatory animals. Immunohistochemical analysis of ovaries from gravid and non-gravid animals demonstrates that EPF is found in the capillaries, interstitial spaces and secretory cells of the corpus luteum. It is concluded that the spatiotemporal pattern of EPF activity described strongly indicates that maternal recognition of pregnancy in marsupials is mediated, at least in part, by EPF. Because the endocrinological milieu is the same in pregnant and non-pregnant marsupials, the possibility of using marsupials as an experimental system for studying EPF function unconfounded by hormonal effects is presented.

\section{Introduction}

Pregnancy in polyovular marsupials is unusual in several respects. Parturition occurs after a brief gestation period that typically falls within the luteal phase of oestrus. Therefore, pregnancy does not interrupt the oestrous cycle, as it does in eutherian mammals. In most marsupials, it is lactation that suppresses ovarian activity; removal of pouch young abrogates this suppression and oestrus resumes (for a review, see Tyndale-Biscoe and Renfree, 1987).

Marsupial pregnancy has certain features that indicate that the gravid animal does not recognize her pregnant status. The conceptus is surrounded by an extracellular coat ('shell'), which restricts cellular contact between the embryo and uterus to the 2-10 day implantation period that immediately precedes parturition. The similarity in plasma progesterone concentrations between pregnant and nonpregnant animals during the luteal phase of the oestrous cycle (reviewed in Tyndale Biscoe and Renfree, 1987, and Tyndale-Biscoe, 1997; Hinds, 1989, 1990; Fletcher, 1989;

Email: Yolanda.P.Cruz@Oberlin.edu

*Present address: Department of Zoology, University of Melbourne, Royal Parade, Melbourne 3010, VIC, Australia
Hinds and Selwood, 1990) has been used as evidence against maternal recognition of pregnancy in marsupials. This situation contrasts markedly with that in eutherians, in which progesterone concentrations increase sharply at an early stage and remain high during pregnancy.

There are differences between the uteri of gravid and nongravid marsupials. In the uteri of polyovular marsupials, significant histological changes occur specifically during pregnancy (Cruz and Selwood, 1993, 1997), despite the unchanged hormonal milieu. Similarly, important differences have also been reported among monovular marsupials, in which only one of the two uteri in a female is gravid during pregnancy (for a review, see Renfree, 2000).

Early pregnancy factor (EPF) has important characteristics that render it an excellent candidate for an early chemical signal between the embryo and mother. EPF is detectable in maternal serum within $24 \mathrm{~h}$ of fertilization in all species studied (for a review, see Morton, 1998); it appears within $12 \mathrm{~h}$ of embryo transfer, and is not detected within $24 \mathrm{~h}$ of death or removal of the embryo (Morton et al., 1987). In addition to being closely linked with embryonic well-being, EPF is required for survival of the embryo during the preand peri-implantation stages of pregnancy (Igarashi, 1987; Athanasas et al., 1989; Athanasas-Platsis et al., 1991, 2000). Moreover, the documented immunosuppressive functions 
of EPF (Noonan et al., 1979; Morton, 1998; Morton et al., 2000; Zhang et al., 2000) indicate that it may play a role in preventing maternal recognition of the embryo as an allograft.

The present investigation was undertaken to determine whether a specific association between EPF and pregnancy could be established in the dasyurid marsupial, Sminthopsis macroura, to support the histological evidence that the gravid uterus is distinguishable from the non-gravid uterus in this species (Cruz and Selwood, 1997) and in another dasyurid, Antechinus stuartii (Cruz and Selwood, 1993). The possible involvement of EPF in marsupial pregnancy was investigated for the first time in $S$. macroura because the period of gestation is only 10.7 days (Selwood and Hickford, 1999). The classical detection protocol for EPF, the rosette inhibition test, was used (Morton et al., 1974, 1976; Rolfe et al., 1984; Cavanagh and Morton, 1996). This test is based on the capacity of lymphocytes, in the presence of guinea-pig serum as a source of complement, to bind heterologous erythrocytes to their cell surface (rosette formation). Rosette formation can be inhibited in a dosedependent manner when lymphocytes are incubated with an immunosuppressive anti-lymphocyte serum (Bach and Antoine, 1968). A modification was incorporated into the assay after the discovery that pre-incubation of lymphocytes in serum obtained from pregnant mice decreased their already compromised capacity to form rosettes in the presence of anti-lymphocyte serum (Morton et al., 1974, 1976). Despite recent molecular characterization of EPF (Cavanagh and Morton, 1994), the rosette inhibition test remains the only useful method for detecting the presence of EPF at concentrations in which it normally appears in vivo (Morton, 1998).

\section{Materials and Methods}

\section{Serum samples}

Serum samples were obtained from pregnant and nonpregnant $S$. macroura raised in a breeding colony maintained by L. Selwood at La Trobe University (Selwood and Hickford, 1999). The reproductive status of the females was assessed each day by evaluating body weight and urine. Urine was tested for the presence of cornified cells from the lateral vaginae (oestrus) and of polymorphonuclear lymphocytes (ovulation). A decrease in body weight coincident with an abundance of vaginal cells and lymphocytes indicated ovulation (Selwood and Woolley, 1991). Females in mid-oestrus were pair-mated for the next 2 or 3 days and mating was confirmed by the presence of spermatozoa in their urine. The time of monitoring on the day of ovulation was set as $t=0$ (Selwood and Hickford, 1999).

Pregnancy was confirmed by the presence of, and staged by the developmental state attained by, the embryos collected, which were used in other studies. Blood was obtained by puncture of the posterior vena cava in animals anaesthetized with halothane (Rhone Merieux, Australia) delivered in oxygen at $200 \mathrm{ml} \mathrm{min}{ }^{-1}$ with a Fluorotech 3 vaporizer (Cyprane Limited, Keighley, Yorkshire). Freshly collected blood was allowed to clot in a sterile microcentrifuge tube for $30 \mathrm{~min}$ at room temperature, centrifuged at approximately $8000 \mathrm{~g}$ for $10 \mathrm{~min}$ and frozen at $-20^{\circ} \mathrm{C}$ to obtain serum samples for EPF testing. Animals were killed by exsanguination or by anaesthetic overdose. A total of 24 animals was used, two of which represented each of the first 10 days of the 10.7 day gestation period (except for day 2, in which only one animal was available, and day 6 , in which three animals were available) and the pre-ovulation period. In addition, two non-pregnant animals were used as controls.

Guidelines for the care and use of animals in research from the Australian National Health and Medical Research Council, the Bioethics Committee of La Trobe University, and the Oberlin Institutional Animal Care and Use Committee were followed in this study.

\section{Rosette inhibition test}

The rosette inhibition test was used to assay serum samples from $S$. macroura for EPF activity. The test is well documented (Morton et al., 1974, 1976; Rolfe et al., 1984; Cavanagh and Morton, 1996) and only specific agents used in the present study are described. Spleen cells were obtained from outbred virgin female Quackenbush mice (Animal Resources Centre, Canning Vale, Western Australia), guinea-pig serum was pooled from six male donors (Rolfe et al., 1984) and human erythrocytes were obtained from a single donor. The anti-lymphocyte serum used in this study was monoclonal rat anti-mouse Lyt 1 (CD5; ATCC TIB 104) hybridoma-conditioned medium (Rolfe et al., 1984). Hybridomas, like the parent myeloma cell lines, produce EPF (Quinn et al., 1990) which was removed from the conditioned medium by passage through a $\mathrm{C}_{18}$ Sep-pak cartridge (Waters Corporation, Milford, MA) activated according to the manufacturer's instructions and equilibrated with PBS $\left(0.05\right.$ mol sodium phosphate buffer $\mathrm{I}^{-1}$, $\mathrm{pH} 7.4,0.15 \mathrm{~mol}$ sodium chloride $\mathrm{I}^{-1}$ ) before application of conditioned medium.

The assay was performed as described by Rolfe et al. (1984) and Cavanagh and Morton (1996). A known positive control (rat serum $48 \mathrm{~h}$ post-partial hepatectomy; Quinn et al., 1994) and a negative control (non-pregnant mouse serum) were included in each assay. Washed spleen cells $\left(1.8 \times 10^{7}\right.$ cells per test) were incubated with test or control serum samples, before use in determining the rosette inhibition titre of the anti-lymphocyte serum. Nine four-fold dilutions of anti-lymphocyte serum in Hanks' balanced salt solution (HBSS) were prepared commencing at 1:16 $\times 10^{-9}$. These dilutions were expressed as $\log _{2}$ (reciprocal dilution $\times 10^{-9}$ ), that is $1: 16 \times 10^{-9}=4$. The rosette inhibition titre for each sample was recorded as the highest dilution of anti-lymphocyte serum to inhibit rosette formation between treated spleen cells and human 


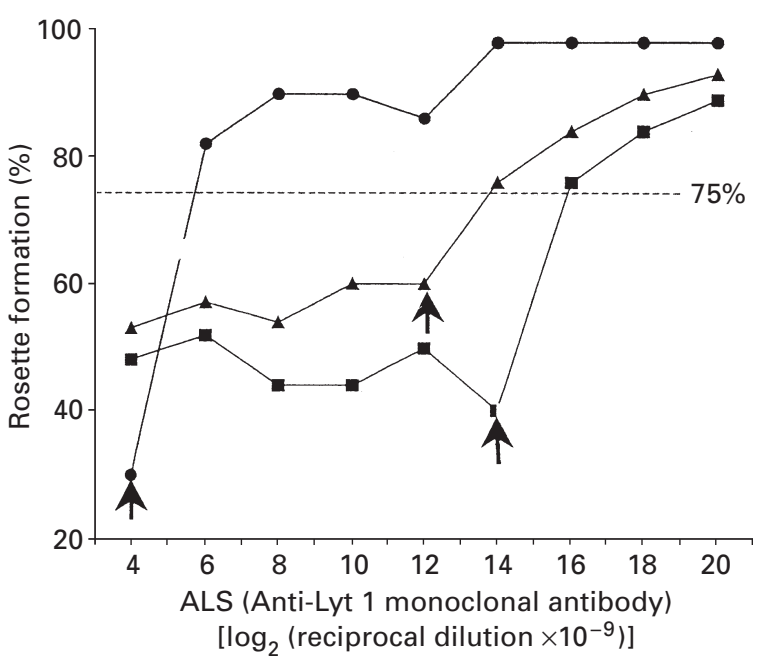

Fig. 1. Rosette inhibition test for detection of early pregnancy factor (EPF) in serum samples from the marsupial Sminthopsis macroura, using anti-Lyt 1 monoclonal antibody as antilymphocyte serum. Mouse spleen cells were pre-incubated in test serum $(\boldsymbol{\Lambda})$, positive control serum $(\boldsymbol{\square})$ or negative control serum (). The number of rosettes formed between human erythrocytes and the treated spleen cells, in each of the anti-lymphocyte serum dilutions shown, was determined and expressed as a percentage of the number of rosettes formed without anti-lymphocyte serum. Results are recorded as rosette inhibition titre (arrows), the highest dilution of anti-lymphocyte serum $\left[\log _{2}\right.$ (reciprocal dilution $\times 10^{-9}$ )] to give rosette formation of $<75 \%$ (samples without anti-lymphocyte serum $=100 \%$ rosette formation): test serum (serum from $S$. macroura on day 2 of pregnancy) rosette inhibition test $=12$, negative control (non-pregnant mouse serum) rosette inhibition test $=4$, and positive control (partially hepatectomized rat serum) rosette inhibition test $=14$. A rosette inhibition test of at least three doubling dilutions of anti-lymphocyte above the negative control, that is, rosette inhibition titre $\geqslant 10$, is indicative of the presence of EPF.

erythrocytes to $<75 \%$ of the number of rosettes formed without anti-lymphocyte serum (see Fig. 1). A positive assay for EPF is defined as a rosette inhibition titre of at least three doubling dilutions of anti-lymphocyte serum above the rosette inhibition titre with the negative control (see Morton et al., 1987). As the negative control rosette inhibition titre was 4 , a rosette inhibition titre of $\geqslant 10$ was positive for the presence of EPF.

The assay is non-quantitative, although it can be used in a semi-quantitative manner by testing dilutions of serum samples and determining the highest dilution to give a positive rosette inhibition titre, that is the limiting positive dilution of EPF activity in serum (limiting dilution). $S$. macroura serum samples were tested at 100 -fold dilutions of $1 \times 10^{-2}$ to $1 \times 10^{-16}$. The limiting dilution was recorded as log reciprocal dilution of a serum sample (Fig. 1).

\section{Immunohistochemistry}

Explanted ovaries from two pregnant animals (days 4 and 7) and one non-pregnant animal were fixed in $4 \%(\mathrm{w} / \mathrm{v})$ paraformaldehyde in PBS, dehydrated in an ascending alcohol series, and blocked in paraffin wax. Sections were cut at $7 \mu \mathrm{m}$ and affixed to poly-L-lysine-coated glass slides; the paraffin wax was removed and the sections were stained with $1 \mathrm{mg}$ affinity-purified rabbit antibody $\mathrm{ml}^{-1}$ against either recombinant EPF (anti-1-101; Somodevilla-Torres et al., 2000), which recognizes both EPF and Cpn 10, or anti-ovalbumin as a control. Five sections from each animal were stained with each primary antibody. The negative control consisted of five sections stained with secondary antibody only.

Paraffin wax was removed by soaking slides in two baths of xylene for 4 min each and in a graded series of alcohols (70-10\%) for 2 min each, ending in Tris-buffered saline (0.05 mol Tris $\mathrm{I}^{-1}, 0.15 \mathrm{~mol} \mathrm{NaCl} \mathrm{I-1}$, pH 7.2-7.4). Permeabilization was achieved by boiling slides twice in 0.01 mol citric acid buffer $\mathrm{I}^{-1}(\mathrm{pH}$ 6.0) for 5 min each, followed by cooling in Tris-buffered saline. Endogenous peroxidase activity was inhibited by incubating permeabilized sections in a mixture of $1.0 \%(\mathrm{v} / \mathrm{v}) \mathrm{H}_{2} \mathrm{O}_{2}$ and $0.1 \%$ $(\mathrm{w} / \mathrm{v}) \mathrm{NaN}_{3}$ in Tris-buffered saline for $10 \mathrm{~min}$; non-specific antibody binding was eliminated by further incubation in 4\% skimmed milk powder in Tris-buffered saline for $15 \mathrm{~min}$ and in $10 \%(\mathrm{v} / \mathrm{v})$ normal (non-immune) goat serum for $20 \mathrm{~min}$. Ovarian sections were exposed to primary antibody for $12 \mathrm{~h}$ at room temperature, washed in five changes of Trisbuffered saline and stained immunohistochemically using biotinylated goat anti-rabbit IgG (secondary antibody) (30 $\mathrm{min}$ ) and streptavidin-horseradish peroxide (HRP) conjugate $(15 \mathrm{~min}$ ) (Zymed Laboratories, South San Francisco, CA). After three rinses in Tris-buffered saline (each after a 5 min soak), ovarian sections were exposed for 5 min to HRP substrate (Zymed Laboratories) consisting of buffered diaminobenzidine and $\mathrm{H}_{2} \mathrm{O}_{2}$, washed in running tap water, counterstained with haematoxylin, dehydrated in an ascending alcohol series and mounted in DePeX.

Photographs were taken on Kodak TMX 100 film through a Nikon Diaphot inverted microscope fitted with a Nikon HFX camera.

\section{Results}

Preliminary rosette inhibition tests were performed using a serum sample from day 2 of pregnancy to examine EPF activity in S. macroura. This sample was tested in parallel with the positive and negative controls. A rosette inhibition titre of 4 was obtained with the negative control sample, of 14 for the positive control sample and of 12 for the pregnancy serum sample (Fig. 2). As a rosette inhibition titre of $\geqslant 10$ is indicative of the presence of EPF (see Morton et al., 1987), the test was positive for EPF. The limiting dilution of EPF activity was determined as shown (Fig. 1). For serum samples from $S$. macroura at day 2 of pregnancy, the rosette inhibition titre was positive to a serum dilution of $10^{-10}$, but negative at $10^{-12}$. The limiting dilution was recorded as 10 (log reciprocal serum dilution).

The limiting dilution of EPF activity was determined in 


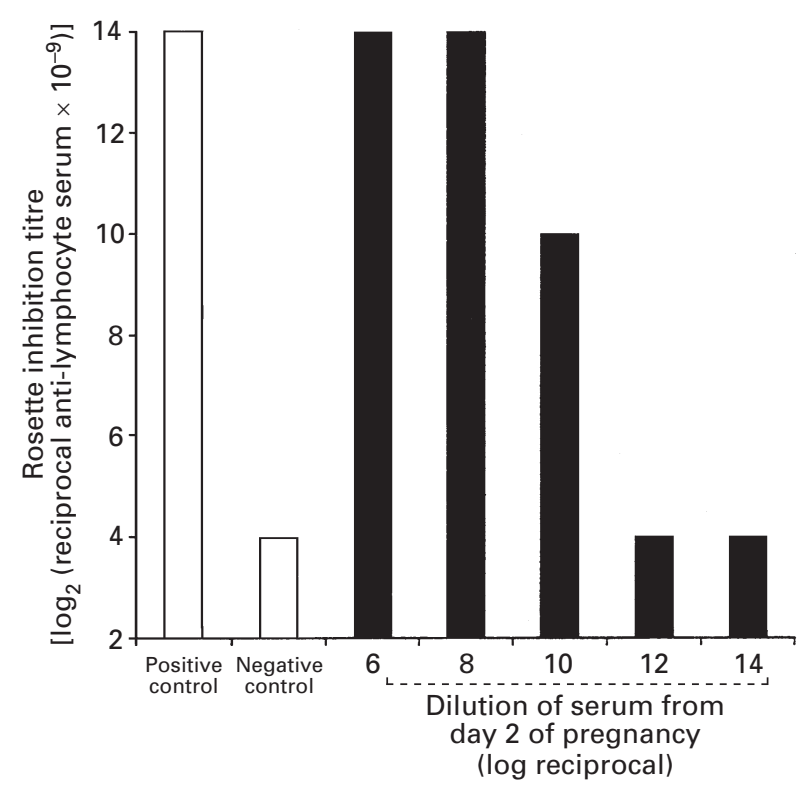

Fig. 2. Determination of the limiting positive dose of early pregnancy factor (EPF) activity in a test serum sample from the marsupial Sminthopsis macroura. A serum sample from S. macroura on day 2 of pregnancy was diluted 100 -fold to $10^{-14}$ and the rosette inhibition titre of each dilution was determined (Fig. 1). The limiting dilution of EPF activity was recorded as log reciprocal of the highest dilution of a sample to give a positive response (that is, rosette inhibition titre $\geqslant 10$ ). Limiting dilution of test serum $=10$. Rosette inhibition titre for the positive (partially hepatectomized rat serum, diluted $10^{-6}$ ) and negative (non-pregnant mouse serum, diluted $10^{-2}$ ) controls are included.

serum samples from 20 pregnant animals, two preovulatory animals and two non-pregnant animals (Fig. 3). EPF was not present in non-pregnant or pre-ovulatory samples, whereas positive results were obtained for all other samples from day 1 to day 9 of pregnancy. EPF was not detected in serum obtained at day 10 of pregnancy. Concentrations of EPF increased steeply during the first $24 \mathrm{~h}$ after fertilization and remained high for the first 3 days of pregnancy. A decrease in EPF concentration was observed on days 4 and 5, and values were maintained at this concentration or slightly higher until day 9. By day 10, EPF had decreased to values seen in non-pregnant animals. The difference between mean serum values on days $1-3$ and on days $4-9$ was highly significant $(P<0.001$; Student's $t$ test $)$.

A distinct immunohistochemical staining pattern was observed in ovaries from animals on day 4 and day 7 of pregnancy, compared with those in ovaries from nonpregnant animals (Fig. 4). Ovaries from pregnant animals revealed a uniform dark staining in capillary lumina or lymphoid sinuses, in the cytoplasm (but not nuclei) of adjacent luteal cells and in interstitial spaces within the corpora lutea (Fig. 4a). In contrast, only light punctate cytoplasmic staining was observed in ovaries obtained from non-pregnant females (Fig. 4c). No staining was observed in ovaries obtained either from pregnant (Fig. 4b) or nonpregnant (Fig. 4d) animals using the negative control antibody.

\section{Discussion}

This is the first report to document the fluctuation of EPF concentrations in serum during pregnancy in a marsupial. Although the rosette inhibition test was originally intended for use with serum samples from eutherian animals (Rolfe et al., 1984), it was found to be effective in detecting EPF in S. macroura serum. This cross-species detection is in accordance with the notion that EPF is not species-restricted (Morton, 1998). The successful use of anti-human-EPF antibodies in immunolocalizing EPF in S. macroura ovaries in the present study reinforces this view.

The presence of EPF in the serum of pregnant (except at day 10) animals and its absence in non-pregnant and preovulatory animals indicate that pregnancy is specifically associated with EPF synthesis. This finding is consistent with the situation in eutherian mammals (Morton, 1998) and supports the finding that certain pregnancy-specific proteins, such as platelet-activating factor, characterize pregnancy in marsupials (Kojima et al., 1993).

The fluctuation of serum EPF concentrations reflects landmark changes during luteinization of ovarian follicles and embryonic development, and in uterine histology during pregnancy. The highest limiting dilutions of EPF were recorded for sera collected during days 1-3 of pregnancy, when the embryo undergoes the first five cleavage divisions and ovarian granulosa cells transform into luteal cells (Selwood and Woolley, 1991). In addition, high serum EPF concentrations appear to signify the appearance of mitotic figures in, and eruption of thecal cells into, the developing corpora lutea (Selwood and Woolley, 1991). Taken together, these observations indicate that cleavage divisions in the early embryo and cellular differentiation in the ovary are associated with high serum EPF concentrations. This conclusion is consistent with those from studies involving pregnant mice (Athanasas-Platsis et al., 1995), mouse embryos in vitro (Athanasas-Platsis et al., 2000) and rats recovering from hepatectomy (Quinn et al., 1994).

The lowest serum EPF concentrations in pregnant S. macroura occur during the prolonged unilaminar blastocyst stage and persist through the early bilaminar blastocyst stage, when mitotic divisions in the embryo occur most slowly (Yousef and Selwood, 1993, 1996). This period of low serum EPF immediately follows the period of highest serum EPF and coincides with significant thickening of the uterine myometrium and luminal epithelium (Cruz and Selwood, 1997), and with enlargement of luteal cells, the cytoplasm of which contains numerous vacuoles during days 4-6 (Selwood and Woolley, 1991). These cellular and histological changes may represent a delayed response to the transient increase in serum EPF. 


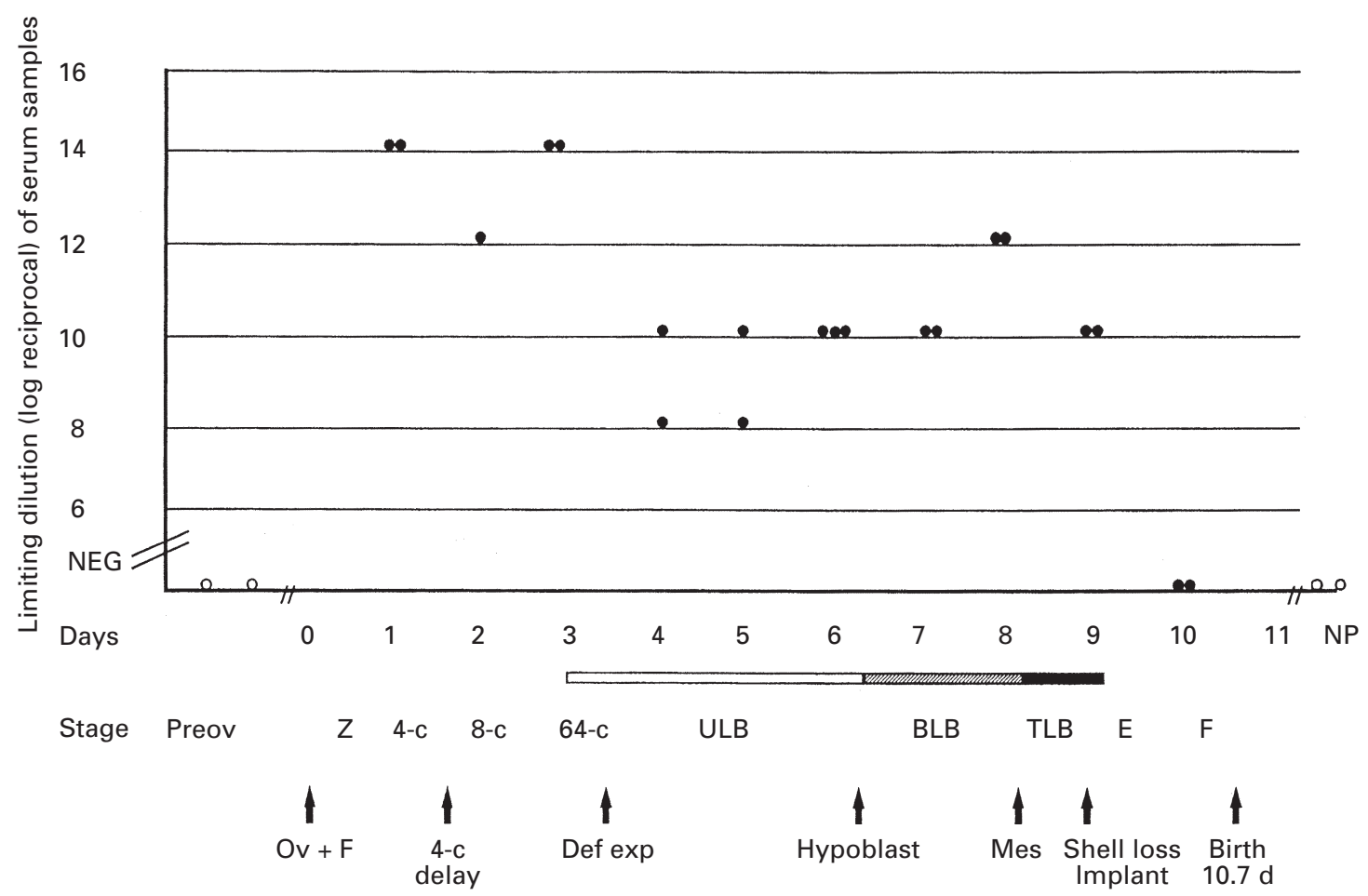

Fig. 3. Serum early pregnancy factor (EPF) activity throughout gestation in the marsupial Sminthopsis macroura. The limiting dilution (log reciprocal) of serum samples from 20 pregnant, two non-pregnant (NP) and two preovulatory (Preov) S. macroura was determined as in Fig. 2. The open, cross-hatched and solid regions of the horizontal bar represent the blastocyst stage, which starts on day 3 and ends at the beginning of day 9 . The days of pregnancy and stages of development are marked along the horizontal axis: Z, zygote; 4-C, four-cell stage; 8-C, eight-cell stage; 64-C, 64-cell stage; BLB, bilaminar blastocyst stage; TLB, trilaminar blastocyst stage; ULB, unilaminar blastocyst stage; E, embryo; F, fetus. Other stages of embryonic development are also given: Ov + F, ovulation and fertilization; 4-c delay, quiescent period at the 4-cell stage; Def exp, definitive expansion of the blastocyst; Mes, mesodermal development; Shell loss, shedding by embryo of shell; Implant, beginning of attachment between choriovitelline placenta and endometrium. Birth occurs on day 10.7. (O) Non-pregnant or preovulatory animals; $(\mathbf{O})$ pregnant animals.

Immunohistochemical examination of $S$. macroura ovaries with an antibody that recognizes both EPF and Cpn 10 revealed marked differences in the staining patterns of tissue from pregnant and non-pregnant animals. In nonpregnant animals, punctate cytoplasmic staining was observed in granulosa cells. This staining pattern is indicative of vesicular structures that are almost certainly mitochondria, as they are distributed uniformly throughout the cytoplasm rather than in a spatial distribution pattern indicative of secretory vesicles, Golgi apparatus or endoplasmic reticulum. The pattern of staining observed is consistent with staining of the mitochondrial matrix protein Cpn 10, which is ubiquitously expressed (SomodevillaTorres et al., 2000) and is a known homologue of EPF (Hartmann et al., 1992).

In ovaries from pregnant animals, the punctate staining pattern was accompanied by areas of dense immunoreactivity within the lumina of capillaries surrounding, and interstitial spaces within, corpora lutea. This overall staining pattern indicates that EPF or Cpn 10 is secreted during pregnancy. Results from the present study showing that EPF is detectable in serum obtained from pregnant $S$. macroura indicate that the immunoreactive material in capillaries and, in part, in the cytoplasm of luteal cells, must be EPF. A similar concordance in immunoreactivity pattern has been observed with human colorectal tissue probed with an antibody recognizing both EPF and Cpn 10 (SomodevillaTorres et al., 2000).

The detection of EPF in pregnant S. macroura has important implications for the study of embryo-maternal signalling in mammals. Because of the hormonal changes that so pervasively characterize pregnancy in eutherian mammals, it has been difficult to study in isolation the interactions between the conceptus and mother that are not hormonally mediated. The present results add to the mounting evidence that maternal recognition of pregnancy occurs in marsupials (Renfree, 2000). Thus these mammals offer a promising experimental system in which to study embryo- 

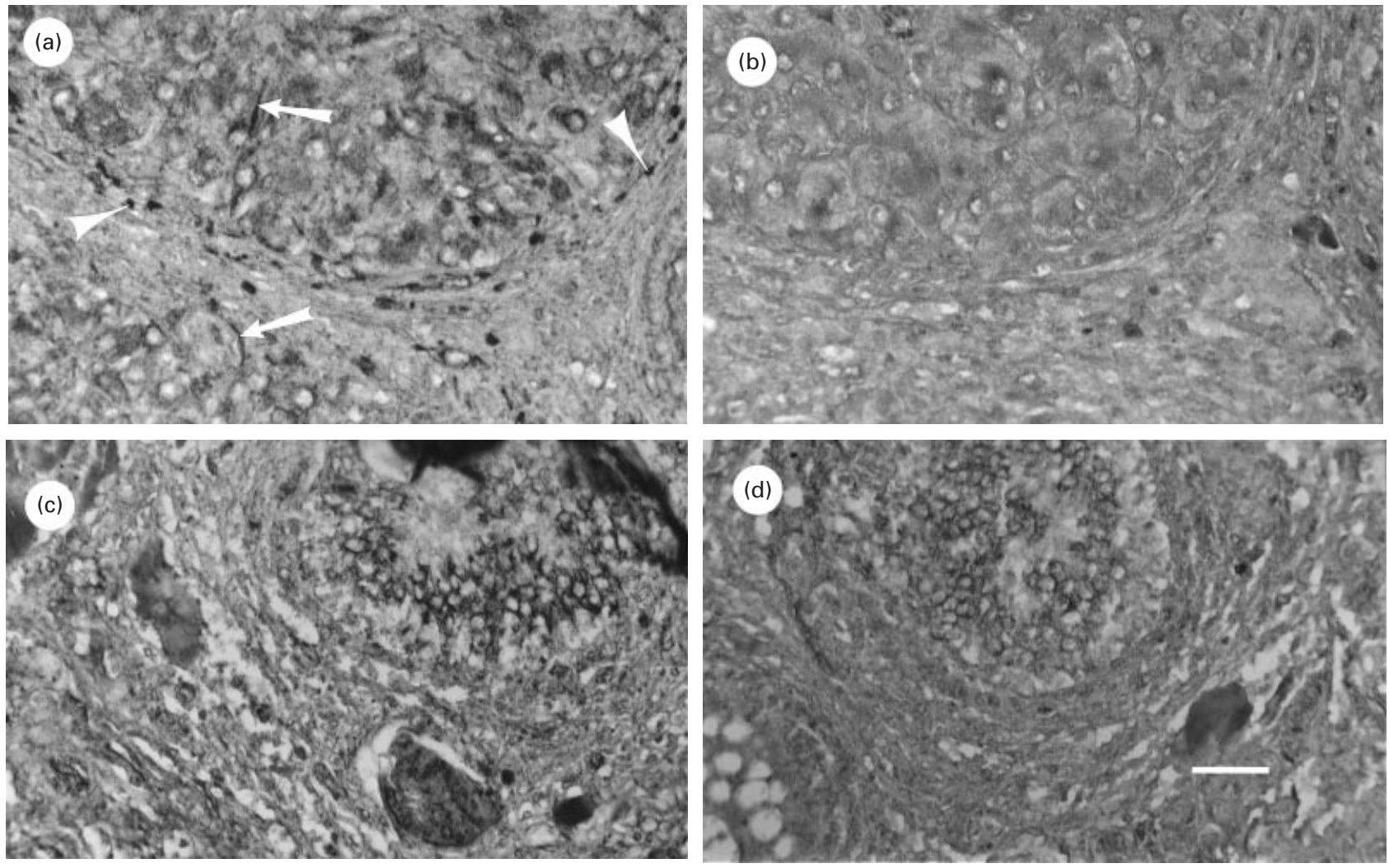

Fig. 4. Ovarian sections from pregnant and non-pregnant Sminthopsis macroura immunostained with rabbit anti-human early pregnancy factor (EPF) antibody (anti-1-101) or anti-ovalbumin antibody. (a) Ovary at day 7 of pregnancy stained with anti-1-101; (b) ovary at day 7 of pregnancy stained with anti-ovalbumin antibody; (c) ovary from a non-pregnant animal stained with anti-1-101; and (d) ovary from a non-pregnant animal stained with anti-1-101. Arrowheads indicate capillaries at periphery of corpus luteum and arrows indicate interstitial spaces. Scale bar represents $30 \mu \mathrm{m}$.

maternal interactions that are not hormonally mediated, such as those putatively mediated by EPF.

The authors are indebted to D. Hickford, B. Zhang, A. Falender and M. Sasaki for technical assistance. This work was supported by a Research Status grant from Oberlin College to Y. P. Cruz and the Australian Research Council to L. Selwood.

\section{References}

Athanasas S, Quinn KA, Wong T-Y, Rolfe BE, Cavanagh AC and Morton H (1989) Passive immunisation of pregnant mice against early pregnancy factor (EPF) causes loss of embryonic viability Journal of Reproduction and Fertility 87 495-502

Athanasas-Platsis S, Morton H, Dunglison GF and Kaye PL (1991) Antibodies to early pregnancy factor retard embryonic development in vitro. Journal of Reproduction and Fertility 92 443-451

Athanasas-Platsis S, Hoskin MJ, Rolfe BE, Cavanagh AC and Morton H (1995) A monoclonal antibody to an early pregnancy factor-induced suppressor factor (EPF-S $)_{1}$ disrupts implantation in mice American Journal of Reproductive Immunology 33 159-166

Athanasas-Platsis S, Corcoran CM, Kaye PL, Cavanagh AC and Morton H (2000) Early pregnancy factor is required at two important stages of development in the mouse American Journal of Reproductive Immunology 43 223-233
Bach JF and Antoine B (1968) In vitro detection of immunosuppressive activity of anti-lymphocyte sera Nature 217 658-659

Cavanagh AC and Morton H (1994) Early pregnancy factor: purification to homogeneity from human platelets and identification as chaperonin European Journal of Biochemistry 222 551-560

Cavanagh AC and Morton H (1996) EPF: embryo detector and molecular chaperone Today's Life Science 8 24-27

Cruz YP and Selwood L (1993) Uterine histology of the dasyurid marsupial, Antechinus stuartii: relationship with differentiation of the embryo Journal of Reproduction and Fertility 99 237-242

Cruz YP and Selwood L (1997) Histological differences between gravid and non-gravid uteri in the dasyurid marsupial, Sminthopsis macroura (Spencer) Journal of Reproduction and Fertility 111 319-325

Fletcher TP (1989) Plasma progesterone and body weight in the pregnant and non-pregnant kowari, Dasyuroides byrnei (Marsupialia: Dasyuridae) Reproduction, Fertility and Development 1 65-74

Hartmann DJ, Hoogenraad NJ, Condron R and Hoj PB (1992) Identification of a mammalian $10-\mathrm{kDa}$ heat shock protein, a mitochondrial chaperonin 10 homologue essential for assisted folding of trimeric ornitihine transcarbomylase in vitro. Proceedings National Academy of Sciences USA 89 3394-3398

Hinds L (1989) Plasma progesterone through pregnancy and the oestrous cycle in the eastern quoll, Dasyurus viverrinus. General and Comparative Physiology 75 110-117

Hinds L (1990) Control of pregnancy, parturition and luteolysis in marsupials Reproduction, Fertility and Development 2 535-552

Hinds LA and Selwood L (1990) Plasma progesterone concentrations during 
pregnancy in the dasyurid marsupial, Antechinus stuartii: relationship with differentiation of the embryo Reproduction, Fertility and Development 2 61-70

Igarashi S (1987) Significance of early pregnancy factor (EPF) on reproductive immunology Acta Obstetrica Gynecologica Japonica 39 189-194

Kojima T, Hinds LA, Muller WJ, O'Neill C and Tyndale-Biscoe CH (1993) Production and secretion of progesterone in vitro and presence of platelet-activating factor (PAF) in early pregnancy of the marsupial, Macropus eugenii. Reproduction, Fertility and Development 5 15-25

Morton H (1998) Early pregnancy factor: an extracellular chaperonin 10 homologue Immunology and Cell Biology 76 483-496

Morton H, Hegh V and Clunie GJA (1974) Immunosuppression detected in pregnant mice by rosette inhibition test Nature 249 459-460

Morton H, Hegh V and Clunie GJA (1976) Studies of the rosette inhibition test in pregnant mice: evidence of immunosuppression? Proceedings of the Royal Society B 193 413-419

Morton H, Rolfe BE and Cavanagh AC (1987) Ovum factor and early pregnancy factor Current Topics in Developmental Biology 23 73-92

Morton H, McKay DA, Murphy RM, Somodevilla-Torres MS, Swanson CE, Cassady AI, Summers KM and Cavanagh AC (2000) Production of a recombinant form of early pregnancy factor that can prolong allogeneic skin graft survival time in rats Immunology and Cell Biology 78 603-607

Quinn KA, Athanasas-Platsis S, Wong T-Y, Rolfe BE, Cavanagh AC and Morton H (1990) Monoclonal antibodies to early pregnancy factor perturb tumour cell growth Clinical and Experimental Immunology $\mathbf{8 0}$ 100-108

Quinn KA, Cavanagh AC, Hillyard NC, McKay DA and Morton H (1994) Early pregnancy factor in liver regeneration after partial hepatectomy in rats: relationship with chaperonin 10 Hepatology 20 1294-1302

Renfree MB (2000) Maternal recognition of pregnancy in marsupials Reviews of Reproduction 5 6-11

Rolfe BE, Cavanagh AC, Forde C, Basti F, Chen C and Morton H (1984) Modified rosette inhibition test with mouse lymphocytes for detection of early pregnancy factor in human pregnancy serum Journal of Immunological Methods 70 1-11
Selwood L and Hickford D (1999) Early cell lineages in marsupial embryos. In Cell Lineage and Fate Determination pp 505-519 Ed. S Moody. Academic Press, New York

Selwood L and Woolley PA (1991) A timetable of embryonic development and uterine changes during pregnancy in the stripe-faced dunnart, Sminthopsis macroura (Marsupialia: Dasyuridae) Journal of Reproduction and Fertility $91213-227$

Somodevilla-Torres MJ, Hillyard NC, Morton H, Alewood D, Halliday J, Alewood PF, Vesey DA, Walsh MD and Cavanagh AC (2000) Preparation and characterization of polyclonal antibodies against human chaperonin 10 Cell Stress and Chaperones 5 14-20

Tyndale-Biscoe CH (1997) Marsupials and modern biology - breaking the paradigms. In Marsupial Biology: Recent Research, New Perspectives pp 1-19 Eds N Saunders and L Hinds. University of New South Wales Press, Sydney

Tyndale-Biscoe CH and Renfree MB (1987) Reproductive Physiology of Marsupials Cambridge University Press, Cambridge

Yousef A and Selwood L (1993) Embryonic development in culture of the marsupials Antechinus stuartii and Sminthopsis macroura (Spencer) during preimplantation stages Reproduction, Fertility and Development 5 445-458

Yousef A and Selwood L (1996) The type and differentiation of cells in vitro from unilaminar and bilaminar blastocysts of two marsupials, Antechinus stuartii and Sminthopsis macroura. Reproduction, Fertility and Development 8 743-752

Zhang B, Harness J, Somodevilla-Torres MJ et al. (2000) Early pregnancy factor suppresses experimental autoimmune encephalomyelitis induced in Lewis rats with myelin basic protein and in SJL/J mice with myelin proteolipid protein peptide 139-151 Journal of the Neurological Sciences 182 5-15

Received 31 October 2000.

First decision 21 December 2000.

Accepted 5 February 2001. 